\title{
Psychrophilic pseudomonas in antarctic freshwater lake at stornes peninsula, larsemann hills over east Antarctica
}

\author{
Abhishek Chauhan ${ }^{1 *}$, Pawan K. Bharti ${ }^{2}$, Pankaj Goyal ${ }^{3}$, Ajit Varma ${ }^{3}$ and Tanu Jindal ${ }^{1}$
}

\begin{abstract}
The Larsemann Hills is an ice-free area of approximately $50 \mathrm{~km}^{2}$, located halfway between the Vestfold Hills and the Amery Ice Shelf on the south-eastern coast of Prydz Bay, Princess Elizabeth Land, East Antarctica (69 $\left.30^{\prime} \mathrm{S}, 76^{\circ} 19^{\prime} 58^{\prime \prime} \mathrm{E}\right)$. The ice-free area consists of two major peninsulas (Stornes and Broknes), four minor peninsulas, and approximately 130 islands. The Larsemann Hills area contains more than 150 lakes at different Islands and Peninsulas. Nine lake water samples were collected in a gamma sterilized bottles and were kept in an ice pack to prevent any changes in the microbial flora of the samples during the transportation. The water samples were transported to the lab in vertical position maintaining the temperature $1-4^{\circ} \mathrm{C}$ with ice pack enveloped conditions. Samples were studied for Psychrophilic bacterial count, Pseudomonas spp., Staphylococcus aureus, Salmonella and Total MPN Coliform per $100 \mathrm{ml}$. Psychrophillic counts were found in the range of $12 \mathrm{cfu}$ to $1.6 \times 10^{2} \mathrm{cfu}$ in all the samples. MPN Coliform per $100 \mathrm{ml}$ was found to be absent in all the samples. No growth and characteristics colonies observed when tested for Salmonella and S.aureus. Pseudomonas sp. was found in ST-2 lake water sample as characteristics colonies (Optimum Growth) were observed on selective media at 22 and $25^{\circ} \mathrm{C}$. Further several biochemical tests were also performed to confirm the presence of this Potential Psychrophilic Pseudomonas sp. for its further application in Science and Technology.
\end{abstract}

Keywords: Psychrophilic Pseudomonas, Antarctic freshwater lake, East Antarctica, Stornes peninsula

\section{Background}

Antarctica has for a long time been viewed as a pristine and isolated environment mostly untouched by human activity. Environmental conditions are generally unfavorable in terrestrial Antarctic environments, with low thermal capacity of the substratum, frequent freeze-thaw and wet-dry cycles, low and transient precipitation, reduced humidity, rapid drainage and limited organic nutrients. Despite the extreme conditions, microorganisms including bacteria, archaea, micro fungi and microalgae, are the dominant life form in the Antarctic ecosystems representing relatively simplified system sensitive to perturbations (Niederberger et al. 2008; Gesheva 2009; Gesheva and Negoita 2012). Psychrophilic and psychrotolerant

\footnotetext{
*Correspondence: akchauhan@amity.edu; abhimicro19@rediffmail.com ${ }^{1}$ Amity Institute of Environmental Toxicology, Safety and Management, Amity University, Sector-125, Noida, Uttar Pradesh, India

Full list of author information is available at the end of the article
}

microorganisms have developed various structural and functional adaptations allowing them to survive in harsh environments. In view of the severe environmental conditions prevailing in Antarctica, it has been argued that the production of extracellular compounds would be a particular advantage in reducing inter-species competition. Thus, it was suggested that Polar Regions may be viewed as a vast untapped reservoir of microorganisms with manifold potential application (Manan et al. 2014). Scientists especially microbiologists throughout the world focusing on cold adopted microorganisms known as Psychrophiles which optimally grow at $15^{\circ} \mathrm{C}$. Cold adopted microorganisms are also reported for the effective bioremediation of oil polluted alpine soils (Margesin 2000). Reddy et al. (2003) and Mountfort et al. (1997) have done the extensive work for the microbial life in the polar environment and have been discovered and described new taxa of Psychrophiles. Several strains of bacteria have been isolated from extreme environments of Antarctica. Gram negative

\section{Springer}

(c) 2015 Chauhan et al. This article is distributed under the terms of the Creative Commons Attribution 4.0 International License (http://creativecommons.org/licenses/by/4.0/), which permits unrestricted use, distribution, and reproduction in any medium, provided you give appropriate credit to the original author(s) and the source, provide a link to the Creative Commons license, and indicate if changes were made. 
spore-forming, non-spore forming rods, Gram positive cocci were isolated from the snow, ice, and frozen algae of Antarctica (McClean 1918). Temperature-sensitive molecules and enzymes of psychrophiles have applications in pharmaceuticals. The cryoprotectors synthesized by psychrophilic and psychrotolerant microorganisms are used in agriculture, cosmetics, and medicine. Lakes of Antarctica represent a unique ecosystem and not as much considered then lowland lakes mainly because of their remoteness and the short summer open-water period (Bhat et al. 2011).Although they are protected from direct human impact but from last two decades they are largely affected by airborne contaminants, such as acids and nutrients (Rogora et al. 2006), organic pollutants and heavy metals (Carrera et al. 2002). Bharti and Gajananda (2013) reported that even less impact on soft water high altitude lakes might affect significantly the physical and chemical properties to bring changes in species symphony and plenty of the biota and to origin addition of trace substances in higher trophic microorganisms.

The revival of cultivable microorganisms from lakes of Antarctica is not easy; therefore by using rapid and internationally approved method it is possible to understand the diversity, survival, and activity of microorganisms in Antarctic zone. Darling and Siple (1941) isolated 178 strains from the snow, ice, soil and debris of Antarctica. Cultivation and characterization of microorganisms in Antarctic Lakes have also been studied by Zhang et al. 2008. Molecular approach was also adopted for further identification of Antarctic microorganisms. Reddy et al. (2004) evaluated several samples of cyanobacterial mat collected from various water bodies in Antarctica and isolated thirty-one bacteria that belonged to the genus Pseudomonas. All the isolates were found psychrophilic and out of them three novel species of the genus Pseudomonas as Pseudomonas antarctica sp. nov., Pseudomonas meridiana sp. nov. and Pseudomonas proteolytica sp. nov., identified based on Phenotypic and chemotaxonomic characteristics. Richard et al. (2009)studied the microbiology of polar environment and also reported the cultural conditions, nutritional adaptability of Psychrophiles and other novel microorganisms. Present study was designed to identify the microbiological contamination in the lake samples collected during 30th Indian Scientific Expedition to Antarctica. Microbiological Parameters as per the Indian standard of drinking were selected and Emphasis was given to isolate the psychrophilic microorganisms keeping in view the environmental condition of Antarctica.

\section{Methods}

\section{Sampling site}

Stornes Peninsula of Larsemann Hills in east Antarctica was selected as a sampling site for the present study
(Fig. 1). Water samples were collected from two selected lakes of Stornes Peninsula during 30th Indian Scientific Expedition to Antarctica (ISEA).

\section{Method of collection of water samples}

Gamma irradiated, clean and sterilized bottles $(200 \mathrm{ml}$ capacity) were used for the collection of lake water sample from Antarctica. For dechlorination sodium thiosulphate was added to the clean, dry sampling bottles before gamma sterilization in an amount to provide an approximate concentration of $100 \mathrm{mg} /$ lit in the sample (Chauhan et al. 2015). Aseptic conditions were maintained during the collection of samples. The samples were kept in an ice pack to prevent any changes in the microbial flora of the samples during the transportation. The water samples were transported to the lab in vertical position maintaining the temperature $1-4{ }^{\circ} \mathrm{C}$ with ice pack enveloped conditions.

\section{Media, chemical and reagents}

All the media were procured form Hi-Media Laboratory, Mumbai, India. Procured dehydrated media were used as per the instructions written on the box and growth promotion test of each media carried out before evaluation of samples. Sodium Chloride, Sodium thiosulphate and other chemicals were of analytical grade.Gram-Stain kit and other reagent procured from Difco Laboratories.

\section{Method for the determination of psychrophilic bacterial count}

Serial Dilution Pour plate Method was used for the determination of Psychrophilic Bacterial Count. After proper mixing, collected sample was serially diluted up to $10^{7}$ dilutions. Diluted sample were further inoculated $(1 \mathrm{ml})$ to each Petri dishes in duplicate. About $15-20 \mathrm{ml}$ melted media Plate count agar was used for Psychrophilic Bacterial Count as per the guidelines of Indian Standard (IS: 5402-2002, Reaff: 2007). After solidification plates were incubated in an inverted position at $22^{\circ} \mathrm{C}$ for $24 \mathrm{~h}$. After incubation the plates were observed for the bacterial colonies with the help of Quebec Colony Counter and then calculated in terms of cfu per ml.

\section{Enumeration of coliform bacteria (MPN Coliform/100 ml)}

The most probable number (MPN) technique as per IS1622:1981 was implemented for the enumeration of total coliform. The test procedure included three phases namely presumptive, confirmative and completed phase.

\section{Presumptive test}

For each water sample; 5 tubes of each 10, 1, and $0.1 \mathrm{ml}$ were used. $10 \mathrm{ml}$ sample was inoculated in double strength Mc Conkey broth media and rest 1 and 


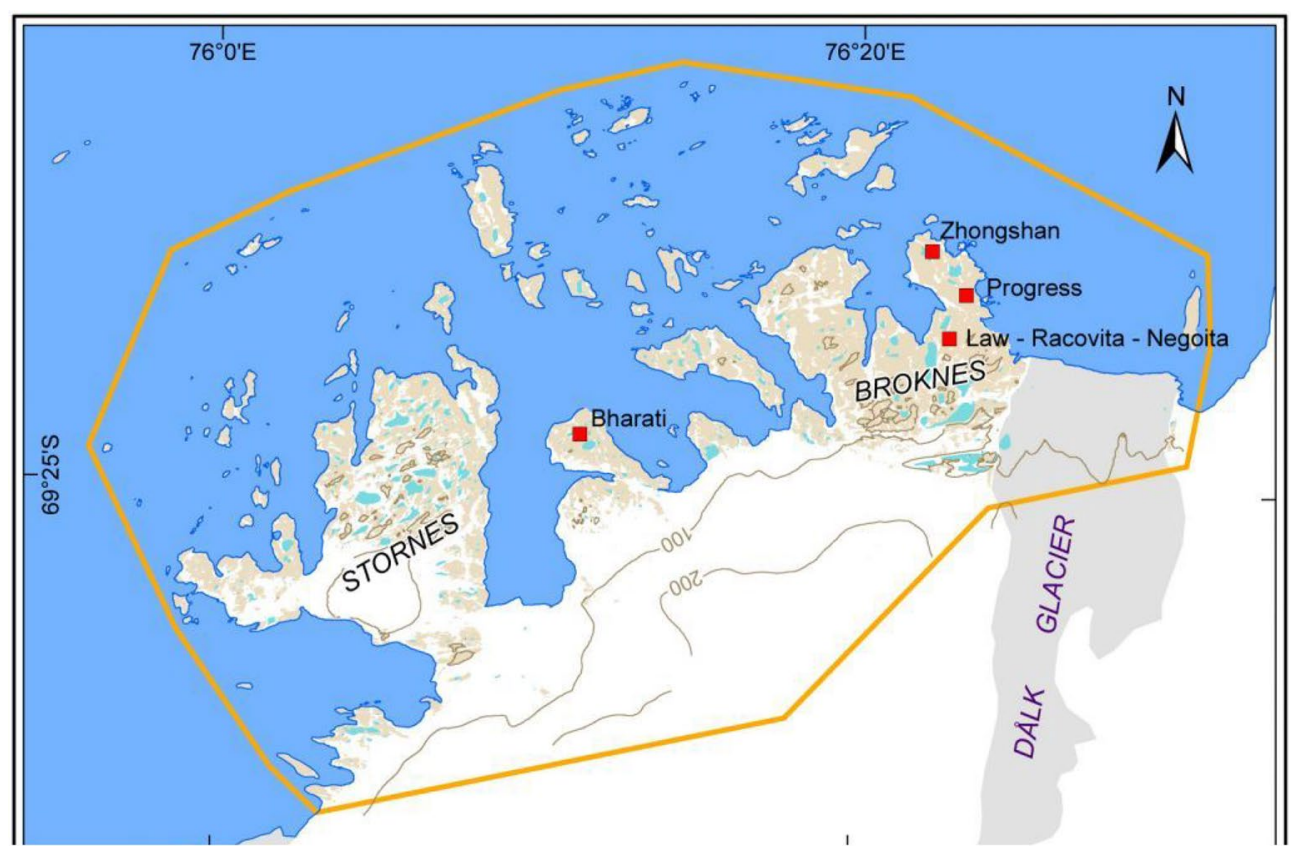

Fig. 1 Location map of Stornes peninsula in Larsemann Hills, east Antarctica

$0.1 \mathrm{ml}$ was inoculated in single strength Mc Conkey broth media. All the inoculated tubes were incubated at $37{ }^{\circ} \mathrm{C}$ for $24-48 \mathrm{~h}$. The test for Coliform is discontinued for further as no growth in all MacConkey broth tubes observed.

\section{Method of detection of Salmonella sp}

For the detection of Salmonella. $250 \mathrm{ml}$ water sample was passed through 0.45 micron filter and the filter paper was inoculated in buffer peptone water and then incubated at $37^{\circ} \mathrm{C}$ for 24 h. $0.1 \mathrm{ml}$ of above enriched sample was inoculated in $10 \mathrm{ml}$ of Rappaport-Vassiliadis (RV) medium and then incubated at $42{ }^{\circ} \mathrm{C}$ for $24 \mathrm{~h}$. Subcultured on the plates of two selective media such as brilliant green agar and bismuth sulphide agar. Plates were observed for characteristic colonies such as pink colonies on brilliant green agar and black metallic sheen colonies with $\mathrm{H}_{2} \mathrm{~S}$ on bismuth sulphide agar plates. Further confirmation through Biochemical and Serological tests was discontinued as no characteristics colonies observed on the plates of selective media (IS: 5887(Part-3) 1999 Reaff.2005).

\section{Method of detection of Staphylococcus aureus}

For the detection of Staphylococcus aureus $250 \mathrm{ml}$ water sample was passed through 0.45 micron filter and the filter paper was inoculated in cooked medium and then incubated at $37{ }^{\circ} \mathrm{C}$ for $24 \mathrm{~h}$. Subcultured on the Mannitol salt agar and Baird parker agar plates. Plates were observed for characteristic colonies such as yellow colonies on Mannitol salt agar plates and black colonies on Baird parker agar plates. Further confirmation through Biochemical and Serological tests was discontinued as no characteristics colonies observed on the plates of selective media IS: 5887(Partt-2) 1976 Reaff.2005.

\section{Method of detection of Pseudomonas aeruginosa}

For the detection of Pseudomonas sp. $250 \mathrm{ml}$ water sample was passed through 0.45 micron filter and the filter paper was inoculated in cetrimide broth and then incubated at $4,15,22,25,37{ }^{\circ} \mathrm{C}$ for $48 \mathrm{~h}$ in individual tubes. Subcultured on the plates of cetrimide agar. Plates were observed for characteristic green colonies, optimum growth were observed at 22 and $25^{\circ} \mathrm{C}$. Further confirmation was done by Gram's staining and Biochemical test as per the guidelines of IS: 13428:2005 (Additional file 1: Table S1).

\section{Results and discussion}

The present research study was carried out to know the microbiological contamination in Antarctic freshwater lake at stornes peninsula, larsemann hills over east Antarctica. Data of collected sample is summarized in Additional file 1: Table S1 and Additional file 2: Table S2. Psychrophillic counts were found in the range of $12 \mathrm{cfu}$ to $1.6 \times 10^{2}$ $\mathrm{cfu}$ in all the samples. MPN Coliform per $100 \mathrm{ml}$ was found to be absent as No Growth in presumptive test was observed, hence sample discontinued for further studies. No any growth and characteristics colonies observed when 
tested for Salmonella and S. aureus. Pseudomonas sp. was found in ST-2 lake water sample as characteristics colonies (optimum growth) were observed on selective media at 22 and $25{ }^{\circ} \mathrm{C}$. Isolated Pseudomonas was further study for its morphological identification. The isolate was identified Gram-negative rod shaped in Gram-staining slide under Laboratory Microscope. Several biochemical tests were carried out for further identification of isolated strain. The observation of all biochemical test of Pseudomonas isolate is given in Additional file 1: Table S1; Figs. 1, 2, 3, 4, 5, 6 and 7. A positive strain of Pseudomonas aeruginosa MTCC 1688 was also used as a positive control to ensure

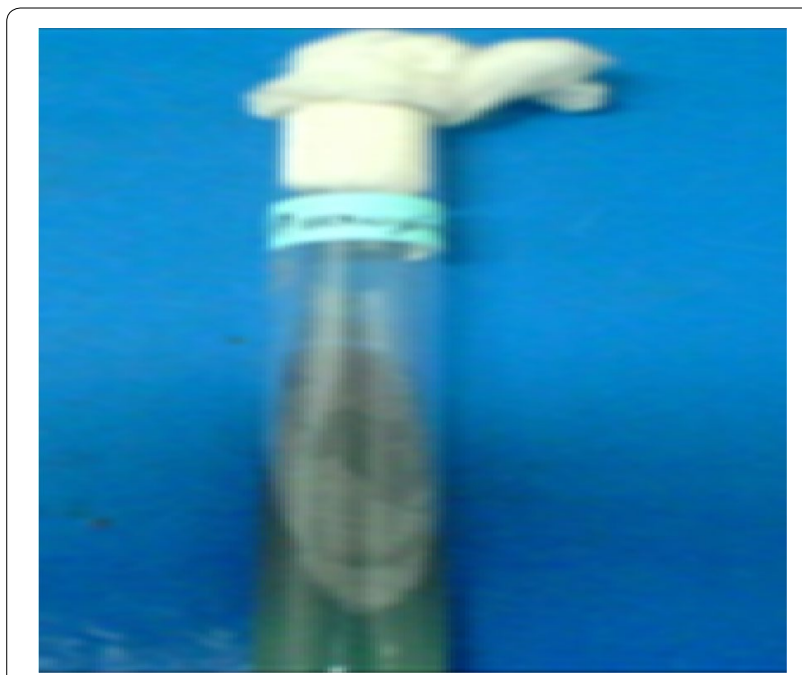

Fig. 2 Growth of isolate on nutrient agar slant

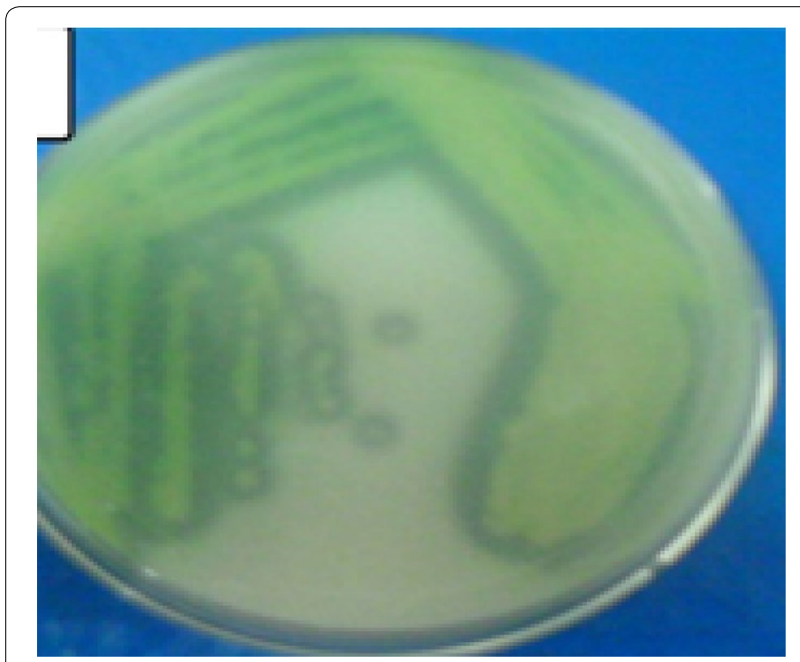

Fig. 3 Characteristics colonies on Cetrimide agar (a selective agar media)

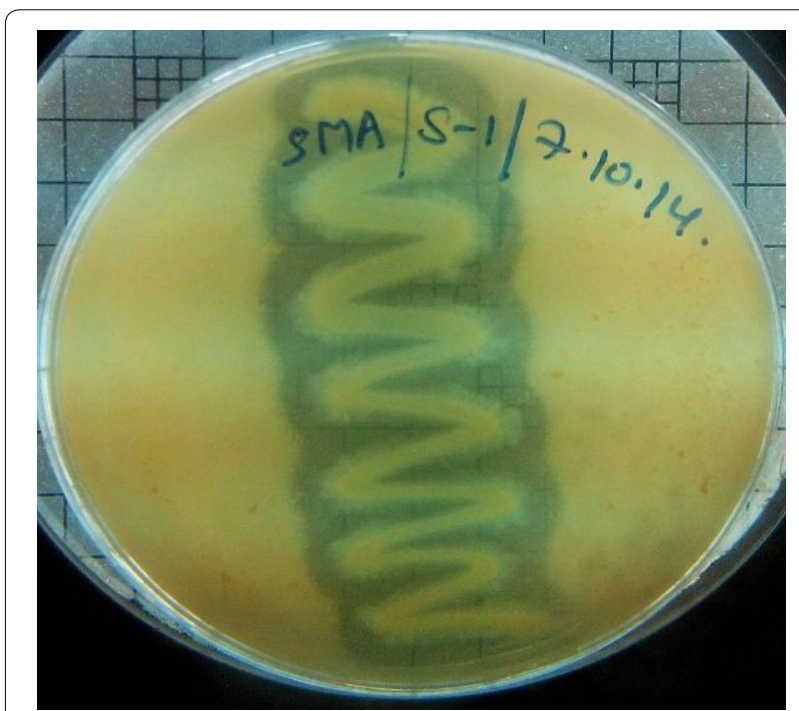

Fig. 4 Casein hydrolysis on skimmed milk agar

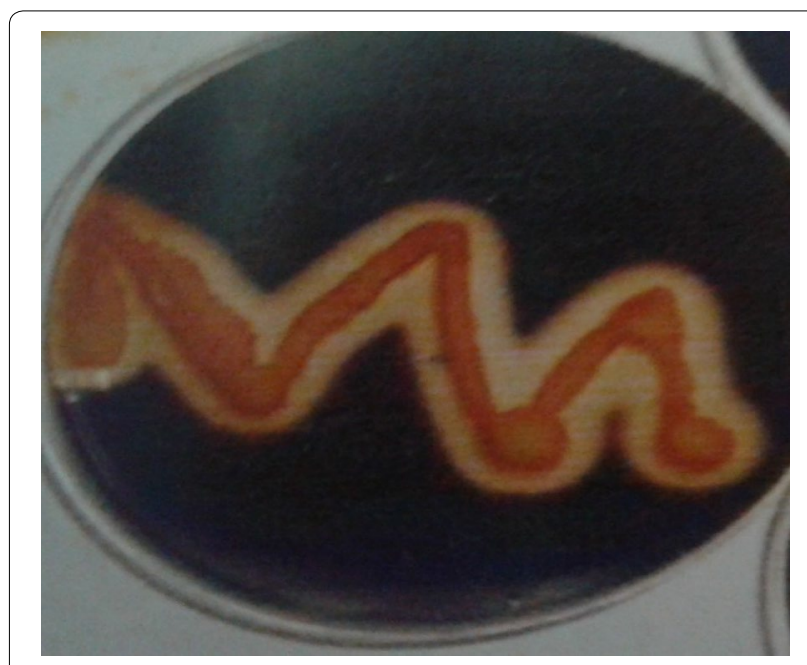

Fig. 5 Starch hydrolysis on starch agar

the laboratory condition during biochemical identification isolated strain. Our study is supported by the research work done by Zhang et al. (2008). They had reported the homology analysis of isolates from Antarctica and identified several close representative group of microorganisms. They also studied the colony morphological characteristics of isolated microorganisms and found that mostly isolates were growing at $4{ }^{\circ} \mathrm{C}$ which also an indicator of presence of Pstchrophilic microorganisms in Antarctica.

\section{Conclusion}

With increasing amounts of research taking place it is becoming clear that Antarctica not only profoundly 


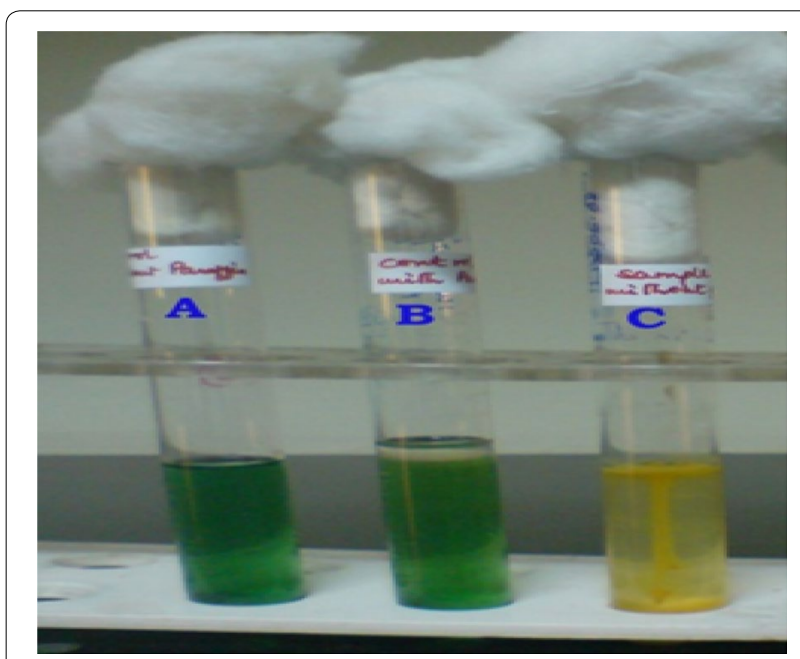

Fig. 6 Hugh and Leifson test: A Media control tube. B Tube having the liquid paraffin (no growth). CTube shows the yellow growth (Oxidative)

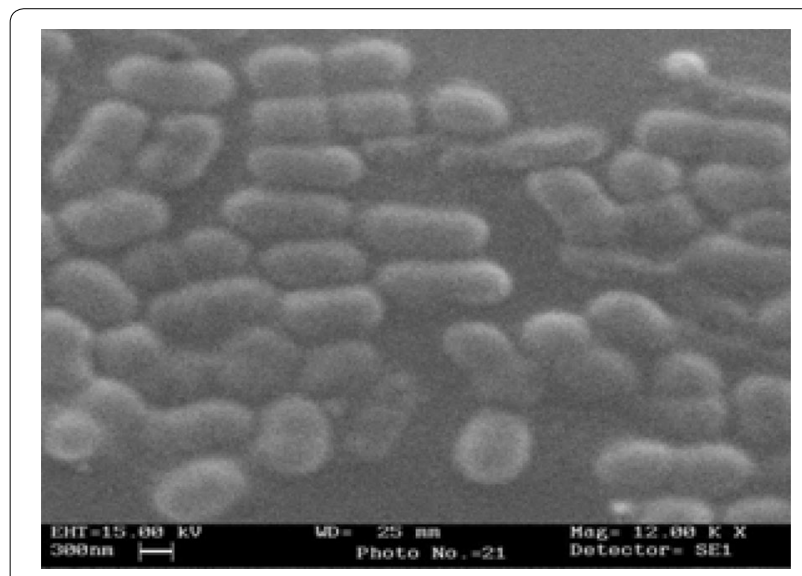

Fig. 7 Scanning electron micrograph (SEM) image of Isolated Pseudomonas sp.

influences us, but that we are globally linked and are having an influence on it too through microbial pollution produced locally and from all over the globe. Most human activity and its associated pollution in Antarctica is highly localized, and waste disposal in the early years was in the form of snow pits, waste dumps, open pit burning, and release of untreated sewage into the oceans. This was the mindset in those times, but has now changed to a more environmentally aware regime. Antarctica is now facing a more serious threat from microbial pollution which began at the time of the industrial revolution. Out of nine samples, only one isolate of Pseudomonas sp. was morphologically and biochemically identified. Presence of this isolate indicates the contamination of fresh water of lake. Coliform organisms, Salmonella and S.aureus were found absent in all the samples which indicate that quality of freshwater of the lake. However, Presence of Gram-negative psychrophylic Pseudomonas isolate specify that there is an urgent need to identify the source of contamination and Hygiene level of Antarctica and residing people. The research outcome also states the requirement of evaluation of Pathogenecity of the isolate and molecular identification for its further use in Science and Technology Globally.

\section{Additional files}

Additional file 1: Table S1. Morphological and Biochemical tests carried out for further identification.

Additional file 2: Table S2. Microbiological Evaluation and Location of lake water sampling points at Stornes Peninsula.

\section{Authors' contributions}

AC and PKB conceived and designed this study. PKB participated in 30th Indian Scientific Expedition to Antarctica and collected the samples. AC and PG analyzed the data. AC wrote and drafted the manuscript. AV and TJ provided their inputs for improving the manuscript quality. All authors read and approved the final manuscript.

\section{Author details}

${ }_{1}^{1}$ Amity Institute of Environmental Toxicology, Safety and Management, Amity University, Sector-125, Noida, Uttar Pradesh, India. ${ }^{2}$ Antarctica Laboratory, R \& D Division, Shriram Institute for Industrial Research, 19, University Road, Delhi 110007, India. ${ }^{3}$ Amity Institute of Microbial Technology, Amity University, Sector-125, Noida, Uttar Pradesh, India.

\section{Acknowledgements}

The authors are grateful to The Ministry of Earth Sciences (MoES), National Centre for Antarctic and Ocean Research (NCAOR) and SIIR for providing opportunity to carried out the study and participation of Dr. Pawan K. Bharti in 30th Indian Scientific Expedition to Antarctica also want to express their gratitude to leaders and all the expedition members for their continuous support and helps.

\section{Competing interests}

The authors declare that they have no competing interests.

Received: 22 January 2015 Accepted: 18 September 2015

Published online: 07 October 2015

\section{References}

Bharti PK, Gajananda KH (2013) Environmental monitoring and assessment in Antarctica. In: Bharti PK, Gajananda KH (eds) Environmental health and problems. Discovery Publishing House, Delhi, pp 178-186

Bhat FA, Yousuf AR, Aftab A, Arshid J, Mahdi MD, Balkhi MH (2011) Ecosystem and microbial populations in Pangong Lake, Himalaya. Int J Biodivers Conserv 3(10):501-511

Carrera G, Fernandez P, Grimalt JO, Ventura M, Camarero L, Catalan J, Nickus $\mathrm{U}$, Thies H, Psenner R (2002) Atmospheric deposition of organochlorine compounds to remote high mountain lakes of Europe. Environ Sci Technol 36(12):2581-2588

Chauhan A, Goyal P, Varma A, Jindal T (2015) Microbiological evaluation of drinking water sold by roadside vendors of Delhi. Appl Water Sci, India. doi:10.1007/s13201-015-0315-x 
Darling CA, Siple PA (1941) Bacteria of Antarctica. J Bacteriol 42:83-98 Gesheva V (2009) Distribution of psychrophilic microorganisms in soils of Terra Nova Bay and Edmonson Point, Victoria land and their biosynthetic capabilities. Polar Biol 32(9):1287-1291

Gesheva V, Negoita T (2012) Psychrotrophic microorganism communities in soils of Haswell Island, Antarctica, and their biosynthetic potential. Polar Biol 35(2):291-297

Indian Standard (IS) (2005) Detection and enumeration of Pseudomonas aeruginosa (Annexure-D)

Indian Standard (IS) 5402 (2002) Reaff: 2007. Microbiology_general guidance for the enumeration of microorganisms colony cont technique at $30^{\circ} \mathrm{C}$

Indian Standard (IS) 5887 (Pt-2) (1976) Reaff: 2005. Isolation, identification and enumeration of Staphylococcus aureus and Faecal Streptococci

Indian Standard (IS) 5887 (Pt-3) (1999) Reaff: 2005. General guidance on methods for the detection of Salmonella

Manan FA, Ibrahim Z, Shahir S (2014) Plants in Antarctica: current and future phytoremediation potential. Jurnal teknologi 69(1):59-65

Margesin R (2000) Potential of cold-adapted microorganisms for bioremediation of oil-polluted Alpine soils. Int Biodeterior Biodegrad 46(2000):3-10

McClean AL (1918) Bacteria of the ice and snow in Antarctica. Nature 102:35-39

Mountfort DO, Rainey FA, Burghardt J, Kaspar HF, Stackebrandt E (1997) Clostridium vincentii sp. nov., a new obligately anaerobic, saccharolytic, psychrophilic bacterium isolated from low-salinity pond sediment of the McMurdo Ice Shelf Antarctica. Arch Microbiol 167:54-60

Niederberger TD, McDonald IR, Hacker AL, Soo RM, Barrett JE, Wall DH (2008) Microbial community composition in soils of Northern Victoria Land, Antarctica. Environ Microbiol 10:1713-1724

Reddy GSN, Prakash JSS, Srinivas R, Matsumoto Gl, Shivaji S (2003) Leifsonia rubra sp. nov. and Leifsonia aurea sp. nov., psychrophiles from a pond in Antarctica. Int J Syst Evol Microbiol 53:977-984

Reddy GSN, Matsumoto GI, Schumann P, Stackebrandt E, Shivaji S (2004) Psychrophilic pseudomonads from Antarctica: Pseudomonas antarctica sp. nov., Pseudomonas meridiana sp. nov. and Pseudomonas proteolytica sp. nov. Int J Syst Evolut Microbiol 54:713-719

Richard B, Hoovera, Elena V, Pikutab (2009) Psychrophilic and psychrotolerant microbial extremophiles in Polar environments a Space Science Office, Mail Code 62, NASA/Marshall Space Flight Center, Huntsville, AL 35812 bNational Space Science and Technology Center, 320 Sparkman Dr., Huntsville, AL 35805, USA

Rogora M, Mosello R, Arisci S, Brizzio MC, Barbieri A, Balestrini R, Waldner P, Schmitt M, Stahli M, Thimonier A, Kalina M, Puxbaum H, Nickus U, Ulrich E, Probst A (2006) Hydrobiologia 562:17-40

Zhang H, Tanabel SH, Nagatal S, Ban S, Imura S (2008) Cultivation and Characterization of Microorganisms in Antarctic Lakes, 978-1-4244-21268/08/\$25.00 @2008 IEEE

\section{Submit your manuscript to a SpringerOpen ${ }^{\odot}$ journal and benefit from:}

- Convenient online submission

- Rigorous peer review

- Immediate publication on acceptance

- Open access: articles freely available online

- High visibility within the field

- Retaining the copyright to your article

Submit your next manuscript at $\boldsymbol{s p r i n g e r o p e n . c o m ~}$ 